\title{
Effect of different light-curing devices and aging procedures on composite knoop microhardness
}

\section{Fernanda Regina Voltarelli(a) Claudia Batitucci dos Santos- Daroz (a) \\ Marcelo Corrêa Alves ${ }^{(b)}$ \\ Alessandra Rezende Peris ${ }^{(c)}$ \\ Giselle Maria Marchi(d)}

(a) MSc, PhD student in Restorative Dentistry; (b) MSc, PhD student in Anatomy; (d)PhD, Professor, Department of Restorative Dentistry - Piracicaba Dental School, University of Campinas (UNICAMP), Piracicaba, SP, Brazil.

(c) PhD, Professor, State University of Amazonas, Manaus, AM, Brazil.
Corresponding author:

Fernanda Regina Voltarelli

Av. Limeira, 901, Areião

Piracicaba - SP - Brazil

CEP: 13414-903

E-mail: fervoltarelli@hotmail.com

Received for publication on Mar 05, 2009

Accepted for publication on Aug 18, 2009

\begin{abstract}
The aim of this study was to evaluate the effect of light-curing devices (Halogen/HAL, Light Emitting Diodes/LED, Argon Laser/LAS and Plasma Arc/PAC) and aging procedures (Mechanical Cycling/MC, Thermal Cycling/TC, Storage/S, MC+TC and MC+TC+S) on the microhardness of bottom/B and top/T surfaces of 2-mm-high composite resin cylinders. The Knoop microhardness test $(25 \mathrm{~g}, 20 \mathrm{~s})$ on both B and T was performed before and after each aging procedure. For B and T, before aging procedures, PAC showed reduced polymerization effectiveness when compared with HAL. In the T, after TC, PAC and LAS had also showed reduced polymerization effectiveness when compared to HAL and LED. For all light-curing devices, $\mathrm{MC}+\mathrm{TC}+\mathrm{S}$ and $\mathrm{S}$ affected the Knoop microhardness values. In the $\mathrm{B}$, no difference could be observed among the aging procedures for PAC. From all light-curing units, PAC may have rendered composites of reduced quality and the storage aging procedures were the most harmful to the polymer hardness.
\end{abstract}

Descriptors: Dental materials; Hardness tests; Dental curing lights; Dental stress analysis. 


\section{Introduction}

Photoactivated composite resins have been developed in an attempt to surpass the limitations of chemically cured systems. ${ }^{1}$ Dentists have a choice of various types of curing lights for the photopolymerization of composites: conventional quartztungsten-halogen (QTH/HAL), light-emitting diode (LED), plasma arc (PAC) or argon laser (LAS) curing lights. These lights have different characteristics and advantages, but the optimal light-curing unit for the photopolymerization of composites has not yet been determined. ${ }^{2}$

The QTH is the most traditional dental lightcuring unit. It produces light by incandescence. ${ }^{3,4}$ Filters are needed to restrict the emitted light to the blue region of the spectrum for the polymerization of composite resins. ${ }^{5}$ One of the benefits of using the QTH is low cost technology. ${ }^{6}$ However, one of the drawbacks of using these units is the limited effective lifetime. ${ }^{3,5}$ The bulb, reflector and filter can degrade over time because of the high operating temperatures and the large amount of heat generated..$^{4,5}$

LED curing lights use gallium nitride semiconductors that produce a blue light when subjected to an electrical current, ${ }^{7}$ in a narrow band with peak emission of $470 \mathrm{~nm} .{ }^{8}$ One of the advantages of LEDs is that they consume very little energy during the light emitting process allowing them to be powered by rechargeable batteries. ${ }^{9}$ Recently, the second and the third generation of LEDs have been introduced. These new generations of LED have a higher power density and broader light spectrum, respectively, compared to the first previous generation of LED. ${ }^{7}$

The argon laser curing units produce usable energy by exciting ions in the argon-filled resonating chamber. ${ }^{3}$ Instead of providing a continuous wavelength of energy, the argon laser delivers energy through a variety of wavelengths that fall within the absorption range required by CQ: 454, 458, 466, 472, 488 and $497 \mathrm{~nm} .{ }^{7,10}$ Because it generates little infrared output, little heat is produced. ${ }^{3,7,10}$ However, the high cost of these units and their limited lifetime serves as a deterrent for many potential buyers. ${ }^{10}$

The plasma arc curing units were introduced with the expected advantage of reduced time spent on curing composite resins. The light emitted from the lamp passes through a filter in order to obtain visible light with a peak wavelength of around $470 \mathrm{~nm} .{ }^{11,12}$ However, investigations of the efficacy of PAC units have demonstrated, in some cases, that the curing time is too short to provide optimal polymerization.

Deterioration of the restoration could occur due to chemical, thermal and mechanical load stresses. ${ }^{13}$ These load stresses could accelerate the deterioration of the composite resin and dictate the behavior of materials exposed to stresses similar to those found in the oral environment. ${ }^{14}$

There is a lack of research in literature that compares the four light sources currently available (HAL, LED, LAS and PAC) and a lack of standardization of aging procedures (MC, TC and S). Therefore, the aim of the present study was to evaluate the effectiveness of the different light-curing units and the effect of thermal, mechanical and storage aging on the Knoop microhardness of a composite resin.

\section{Material and Methods Power density calculation}

The real power density was calculated for each light source, within the range of absorption of the CQ (450-490 nm), ${ }^{15}$ and their approximations as well. First, the spectrum emitted by each light source was analyzed using a spectrometer (USB 2000, Ocean Optics. Inc., Dunedin, FL, USA). Then, a potentiometer (Power Meter Ophir, Ophir Optronics Inc., Danver, MA, USA) was used to check the potency of each light source. This value was divided by the area of the tip of the corresponding unit. This way, it was possible to obtain the intensity of total light emitted. The software Origin 6.1 (OriginLab Corp., Northampton, MA, USA) gave the total intensity correlated with the spectrum previously appraised through the construction of a graph. In the graph the $\mathrm{X}$ axis represented the wavelength $(\mathrm{nm})$ and the $\mathrm{Y}$ axis represented the light intensity $(\mathrm{mW} /$ $\mathrm{cm}^{2}$ ). This data allowed for the selection of a specific range and, through integral calculation of the area, verification of the light intensity emitted from the wavelength examined. 
The photoactivation of the $\mathrm{Z} 250$ resin composite was carried out according to the manufacturer's recommendation, using 2-mm-thick increments under halogen lamp units with an exposure time of $20 \mathrm{sec}-$ onds and energy density of $6.04 \mathrm{~J} / \mathrm{cm}^{2}$. Applying the calculation formula for energy density $(\mathrm{ED}=\mathrm{mW} /$ $\mathrm{cm}^{2} \mathrm{X}$ seconds/1000), and using the value of light intensity emitted by each unit in the range of absorption of camphorquinone, we could approximate the power densities through the adjustment of exposure times. This way, the exposure times obtained for each light source were: HAL - 20 seconds, LED 10 seconds, LAS - 30 seconds and PAC - 6 seconds.

\section{Specimen fabrication}

A metallic cylindrical matrix (diameter of $5 \mathrm{~mm}$ and height of $2.0 \mathrm{~mm}$ ) was used to fabricate 200 specimens of composite resin Filtek Z250 (3M ESPE Dental Products, St. Paul, MN, USA), color A2. The specimens were divided into 20 groups $(\mathrm{n}=10)$ according to the light source (HAL, LED, LAS and $\mathrm{PAC})$ and aging procedures (MC, TC, S, MC+TC, $\mathrm{MC}+\mathrm{TC}+\mathrm{S})$.

The composite resin specimens were made using one horizontal increment, photopolymerized with the tip of the unit in contact with the top surface of the matrix using one of the light sources: Halogen lamp (OPTILUX 501, Demetron/Kerr Corp., Orange, CA, USA); Light Emitting Diodes (Freelight Elipar 2, 3M ESPE, Seefeld, Germany); Argon Laser (AccuCure 3000, LaserMed, West Jordan, UT, USA); Xenon Plasma Arc (Apollo 95E Elite, DMD - Dental Medical Diagnostic Systems, Westlake Village, CA, USA).

\section{Aging procedures}

During the thermal aging (TC), the specimens were submitted to 1,000 cycles $^{14}$ in distilled water, using a thermal cycling machine (MCT3-Plus, Instrumental, São Paulo, SP, Brazil). In each cycle the specimen was bathed for $60 \mathrm{~s}$ in water varying in temperatures from $5 \pm 2{ }^{\circ} \mathrm{C}$ to $55 \pm 2^{\circ} \mathrm{C}$, with a transfer time of $5 \mathrm{~s}$.

For the mechanical aging (MC) two-hundred thousand cycles ${ }^{14}$ at a frequency of $2 \mathrm{~Hz}$ (cycles/second) ${ }^{14}$ with a vertical load of $75 \mathrm{~N}^{14}$ were accom- plished using a mechanical cycling machine (ERFOP 10, International Erios, São Paulo, SP, Brazil). During the test, the cylinders were maintained in distilled water at $37^{\circ} \mathrm{C}$.

In the storage aging procedure (S), the specimens were maintained in Hank's saline buffer solution ${ }^{16}$ for 1 year. This solution was employed to simulate the chemical composition of saliva. During the storage period, the samples were kept in hot chambers at $37^{\circ} \mathrm{C}$ and the storage solution was changed every 15 days.

The association between thermal cycling and mechanical loading $(\mathrm{TC}+\mathrm{MC})$, and among all aging procedures $(\mathrm{TC}+\mathrm{MC}+\mathrm{S})$ was carried out using the same methodology as previously described.

\section{Knoop microhardness test}

Approximately 24 hours after sample fabrication and after each aging procedure, Knoop hardness was measured on the bottom and top surfaces of the specimens using a microhardness tester (Microhardness Tester, Future Tech FM-1E, Future Tech Corp., Tokyo, Japan). A load of $25 \mathrm{~g}$ per $20 \mathrm{~s}$ was applied in five different points in each surface of the specimen.

An average of the five measurements was calculated on each surface and transformed in Knoop hardness number $(\mathrm{KHN})$ using the following formula:

$$
\mathrm{KHN}=14,230 \times \frac{\mathrm{F}}{\mathrm{d}^{2}}
$$

where:

$\mathrm{F}$ is the force in grams (25 grams) and $\mathrm{d}$ is the length of the longest diagonal in micrometers.

\section{Statistical analysis}

One-way Anova was used to compare the effect of light-curing sources. ANOVA applied to the splitplot design tested the effect of light-curing sources and aging procedure. The split-plot design is coherent with the determination method (the aging process was defined after the determination of the lightcuring source).

The analysis of variance tests the difference between, at least, two means for each factor. The Tukey's HSD test was used to compare means at different levels of the factor, when significant in 
the ANOVA. The level of significance adopted was 0.05 .

\section{Results}

Before the aging procedures, all we have is the effect of the different light sources influencing the Knoop microhardness values. Graph 1 demonstrates the comparison of the light sources on the top and bottom of specimens. The effect of the light-curing sources before the aging process was different at the top and the bottom. On the top, two groups of means were formed. The first group (PAC and LAS) has means significantly different from the other group (HAL and LED). On the bottom, three groups were formed. The first group was LED, the second group was HAL and LAS and the third group was PAC.

In other words, the existence of differences between the light-curing sources on top and bottom in the initial phase shows the importance of the subdivision of the study in order to compare the effects of aging and light-curing sources. After aging, the effects of both aging procedures and light-curing sources on the Knoop microhardness values were tested. The analysis of variance showed a significant interaction between light-curing units and aging. When aging procedures on the top surface were compared (Table 1), it was observed that, for all light sources, the groups stored for 1 year $(\mathrm{MC}+\mathrm{TC}+\mathrm{S}$ and S) had reduced Knoop microhardness values when compared to the other groups.

The differences between light-curing sources in each aging procedure at the top side are illustrated in Graph 2, corroborating the previous table.

In the comparison of the different aging procedures on the bottom surface (Table 2), it was observed that, for HAL, LED and LAS, the groups that were stored for 1 year $(\mathrm{MC}+\mathrm{TC}+\mathrm{S}$ and $\mathrm{S})$ also had reduced Knoop microhardness values when compared to the other types of aging procedures. For PAC, the aging procedures did not differ among them.

The differences between light-curing sources in each aging procedure on the bottom side are illus-
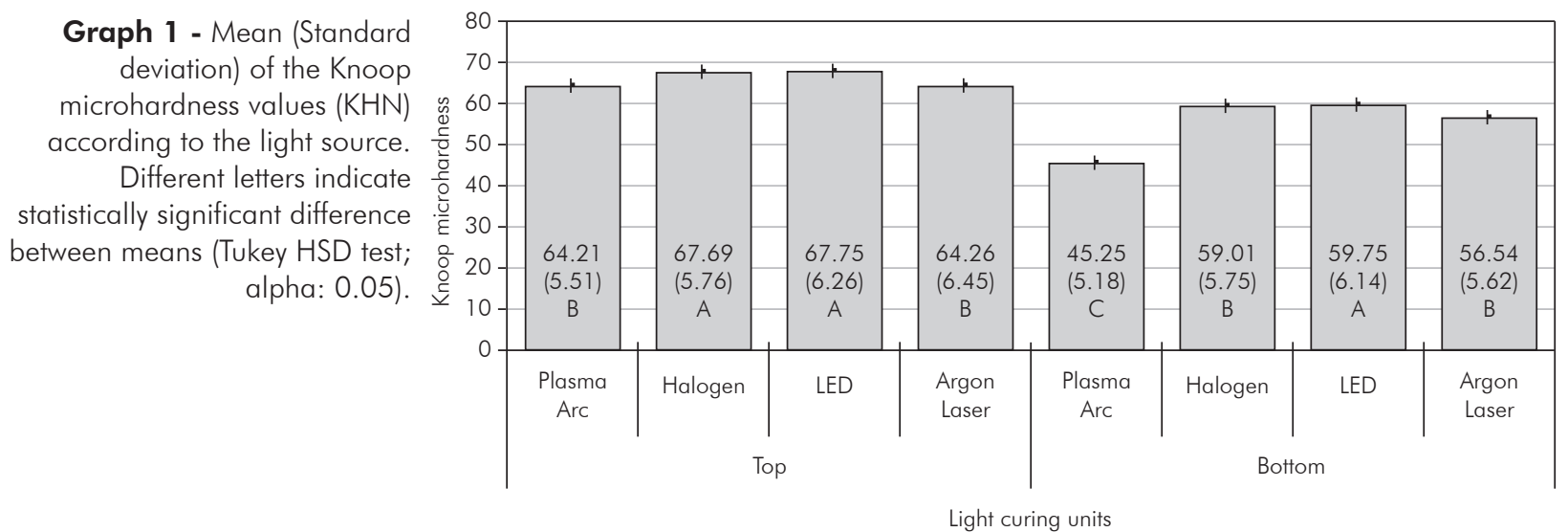

Table 1 - Knoop microhardness values $(\mathrm{KHN})$ according to aging procedures and light-curing units on the top surface.

\begin{tabular}{|c|c|c|c|c|}
\hline \multirow{2}{*}{$\begin{array}{l}\text { Aging } \\
\text { procedures }\end{array}$} & \multicolumn{4}{|c|}{ Light-curing units } \\
\hline & Halogen & LED & Argon Laser & Plasma Arc \\
\hline$M C$ & $70.55 \mathrm{Aa}(3.11)$ & 71.18 Aa (1.93) & $66.00 \mathrm{Ba}(1.94)$ & $66.94 \mathrm{ABa}(3.51)$ \\
\hline$M C+T C$ & 73.08 Aa (3.63) & 73.39 Aa (2.00) & $72.64 \mathrm{Aa} \mathrm{(3.89)}$ & $70.26 \mathrm{Aa}(6.34)$ \\
\hline $\mathrm{MC}+\mathrm{TC}+\mathrm{S}$ & $51.60 \mathrm{Ba}(5.51)$ & $51.18 \mathrm{Ba}(5.22)$ & $51.39 \mathrm{Ca}(5.90)$ & $52.16 \mathrm{Ca}(4.11)$ \\
\hline $\mathrm{TC}$ & $70.38 \mathrm{Aa}(2.38)$ & $69.83 \mathrm{Aa}(5.12)$ & $62.97 \mathrm{Bb}(2.25)$ & $62.31 \mathrm{Bb}(5.09)$ \\
\hline S & $52.04 \mathrm{Ba}(5.45)$ & $51.23 \mathrm{Ba}(5.64)$ & $49.24 \mathrm{Ca}(3.15)$ & $48.80 \mathrm{Ca}(4.94)$ \\
\hline
\end{tabular}

Different letters indicate statistically significant differences (Tukey; $\alpha=5 \%$ ). Capital letters compare aging procedures; Low case letters compare light curing units. 
Table 2 - Knoop microhardness values (KHN) according to aging procedures and light-curing units on the bottom surface.

\begin{tabular}{|c|c|c|c|c|}
\hline \multirow{3}{*}{$\begin{array}{c}\begin{array}{c}\text { Aging } \\
\text { Procedures }\end{array} \\
\text { MC }\end{array}$} & \multicolumn{4}{|c|}{ Light-curing units } \\
\hline & Halogen & LED & Argon Laser & Plasma Arc \\
\hline & $60.17 \mathrm{Aa}(2.57)$ & 61.07 Aa (2.57) & $54.00 \mathrm{Bb} \quad$ (2.35) & $39.30 \mathrm{Ac}(2.59)$ \\
\hline $\mathrm{MC}+\mathrm{TC}$ & 63.27 Aa (2.40) & 62.03 Aa (3.19) & $58.19 \mathrm{ABa}(5.42)$ & $46.33 \mathrm{Ab}(4.03)$ \\
\hline $\mathrm{MC}+\mathrm{TC}+\mathrm{S}$ & $46.20 \mathrm{Ba}(4.93)$ & $47.17 \mathrm{Ba}(6.24)$ & $47.81 \mathrm{Ca}(6.21)$ & $43.92 \mathrm{Aa}(4.62)$ \\
\hline $\mathrm{TC}$ & 63.24 Aa (3.03) & 63.65 Aa (2.97) & $60.02 \mathrm{Aa} \quad(3.48)$ & $45.72 \mathrm{Ab}(3.62)$ \\
\hline$S$ & 43.44 Ba (4.59) & $50.38 \mathrm{Ba}(5.93)$ & $44.41 \mathrm{Ca}$ (4.22) & $44.44 \mathrm{Aa}(6.27)$ \\
\hline
\end{tabular}

Different letters indicate statistically significant differences (Tukey; $\alpha=5 \%$ ). Capital letters compare aging procedures; Low case letters compare light-curing units.

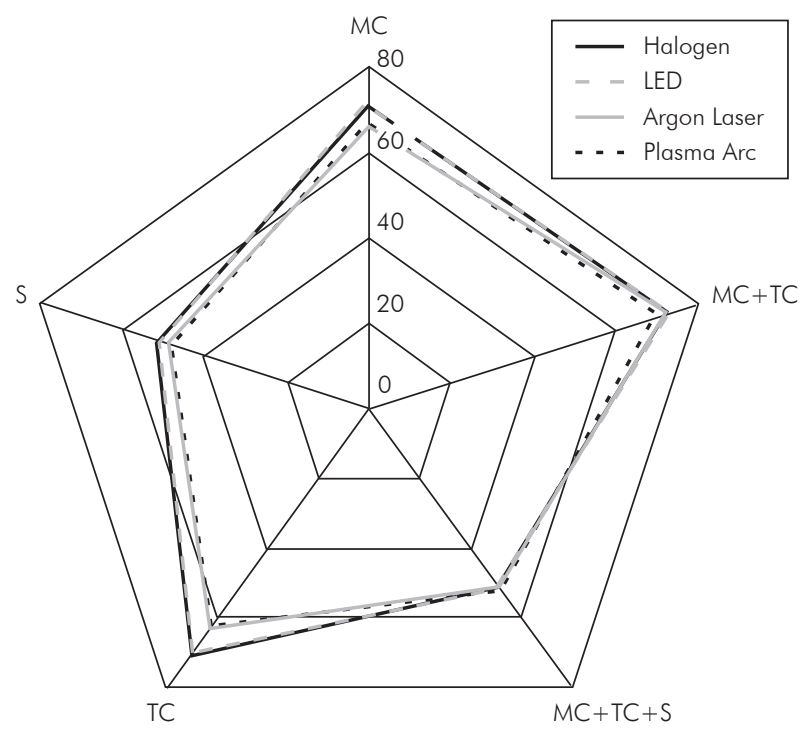

Graph 2 - Mean Knoop microhardness values (KHN) according to the light source after different aging procedures at top side.

trated in Graph 3, corroborating the existence of differences in $\mathrm{MC}, \mathrm{MC}+\mathrm{TC}$ and $\mathrm{TC}$ procedure.

\section{Discussion}

The comparison among the light-curing sources (Graph 1), before the aging procedures, showed that the top surface of composites light-cured with LED and HAL had Knoop microhardness values significantly higher than the ones with LAS and PAC. The bottom surface of composites light-cured with PAC also had significantly reduced hardness values before the aging procedures.

This could be due to the fact that PAC was used with a short exposure time of 6 seconds, besides the emission of a high intensity light. Although it

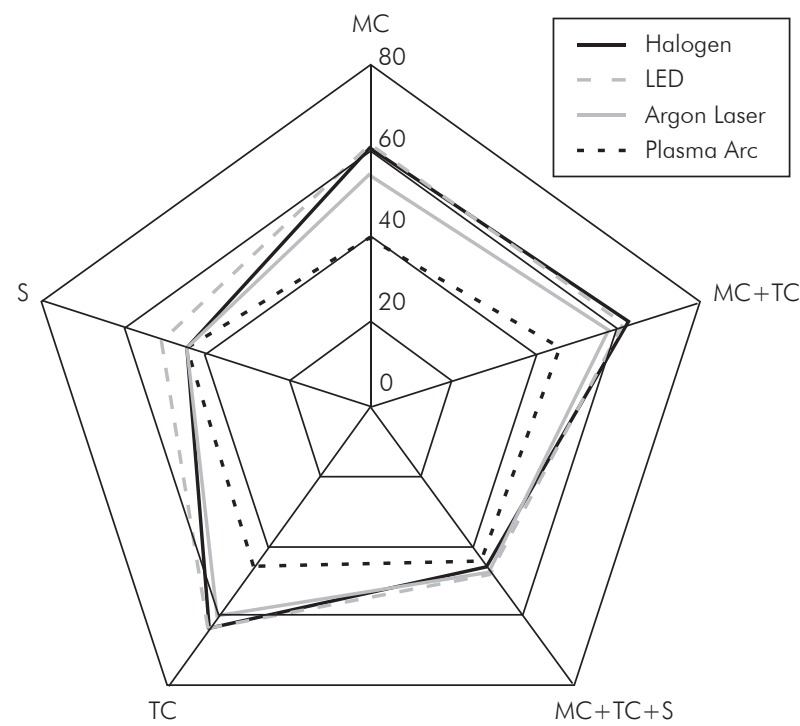

Graph 3 - Mean Knoop microhardness values (KHN) according to the light source after different aging procedures at bottom side.

supplied the same energy density as the other lightcuring units, the exposure time might have been too short for an adequate polymerization of the composite material. This may have affected the extension of cross link bonds and the final size of the polymeric chain. ${ }^{1}$ High intensity lights allow the formation of multiple growth centers in the polymer, ${ }^{17}$ but, with a short exposure time, there is not enough time for polymeric growth.

Also, because the polymerization termination is normally a bimolecular process, loss of radicals is faster when their population is greater, where the termination rate is a square function of radical concentration. Even if the same total number of radicals can be generated with the same energy density, due 
to its shorter life time, each radical will react with fewer double bonds before being annihilated. ${ }^{18}$

In this study, LAS had low light intensity $\left(278 \mathrm{~mW} / \mathrm{cm}^{2}\right)$, and, even being used with a longer exposure time (30 seconds), the Knoop microhardness of the composite material was compromised. Few polymeric growth centers are associated with a slower polymerization and low light intensity, which results in a more linear structure and in less amount of cross link bonds. ${ }^{17}$ In addition, the absorption peak of camphoroquinone is at approximately $470 \mathrm{~nm}$, and the argon ion laser works at a wavelength of $488 \mathrm{~nm}$. This distance between them can make the laser activation inefficient. ${ }^{19}$

When aging procedures in the top surface were compared (Table 1), we observed that, for all light sources, the groups stored for 1 year $(\mathrm{MC}+\mathrm{TC}+\mathrm{S}$ and S) had reduced Knoop microhardness values when compared with the other types of aging. Similar results were found in the bottom surface (Table 2). This reduction in the properties of the restorative composite material after water storage is in agreement with findings by Ferracane et al. ${ }^{20}$ (1998). The absorption of water by the polymer causes a softening of the material through the expansion of the chains and decreasing of the friction forces among the polymer chains. ${ }^{20,21}$ Moreover, degradation of dental composites can be proceeded by hydrolysis of the siloxane bond, ${ }^{21}$ with the possible loss of the filler particles. ${ }^{19,21,22}$

The composites absorb water and release their components into their surroundings. ${ }^{21,23}$ Degradation changes the microstructure by forming pores or openings, weakening the composite material sufficiently to reduce restoration longevity and mechanical properties, as Knoop microhardness. ${ }^{21,23}$

For LAS and PAC, the composite specimens submitted to the association between mechanical cycling and thermal cycling had higher hardness values. This may be explained by both the larger period during which the specimens were exposed to room light before the evaluation of their Knoop microhardness and the influence of the heat generated during the cycling procedures. During the mechanical cycling, the temperature was kept at $37^{\circ} \mathrm{C}$, however physical heat may have been generated by the movement of the vertical load in contact with the sample surface. Both the mechanical and thermal cycling consisted of a period of, approximately, 40 hours. Therefore, the samples submitted to the association between these aging procedures were about 80 hours in test. This larger post-polymerization period and exposure to light might have been responsible for the higher Knoop microhardness value obtained.

Interestingly, for LAS, the hardness of the bottom surfaces of specimens submitted to TC and MC did not differ from those submitted to the association between MC+TC; however those submitted to TC had higher hardness than those submitted to MC (Table 2). Probably, the deleterious influence of the mechanical load may have led to the failure of the bond interface between the filler and resin matrix, which resulted in a decrease of the hardness of the composite material. ${ }^{24}$

Acccording to Braz et al. ${ }^{25}$ (2009), the fracture process presents three phases: crack initiation, slow crack growth and fast fracture. Crack initiation is a phase that is considered more difficult to predict, since it depends on the microstructural properties. ${ }^{25}$ Crack initiation nucleates at heterogeneities on the surface and subsurface, porosities or filler particles within the material, but external cycling loading is able to originate or further develop a crack. ${ }^{25}$

\section{Conclusions}

1. Before aging procedures, the composites lightcured with PAC had inferior Knoop microhardness on both top and bottom surfaces.

2. The aging procedures that involved storage of the specimens $(\mathrm{MC}+\mathrm{TC}+\mathrm{S}$ and $\mathrm{S})$ resulted in a significant decrease in the Knoop microhardness values.

3. On the bottom surface, all of the aging procedures were harmful to the specimens light-cured with PAC.

\section{Acknowledgements}

This study was supported by the State of São Paulo Research Foundation (FAPESP, 03/12592-8). 


\section{References}

1. St-Georges AJ, Swift EJ, Thompson JY, Heymann HO. Curing light intensity effects on wear resistance of two resin composites. Oper Dent. 2002;27(4):410-7.

2. Price RBT, Ehrnford L, Andreou P, Felix CA. Comparison of quartz-tungsten-halogen, light-emitting diode, and plasma arc curing lights. J Adhes Dent. 2003;5(3):193-207.

3. Burgess JO, Walker RS, Porche CJ, Rappold AJ. Light-curing an update. Compend Contin Educ Dent. 2002;23(10):889906.

4. Peris AR, Mitsui FHO, Amaral CM, Ambrosano GMB, Pimenta LA. The effect of composite type on microhardness when using quartz-tungsten-halogen (QTH) or LED units. Oper Dent. 2005;30(5):649-54.

5. Yoon TH, Lee YK, Lim BS, Kim CW. Degree of polymerization of resin composites by different light sources. J Oral Rehabil. 2002;29(12):1165-73.

6. Cefaly DF, Ferrarezi GA, Tapety CM, Lauris JR, Navarro MF. Microhardness of resin-based materials polymerized with LED and halogen curing units. Braz Dent J. 2005;16(2):98-102.

7. Park SH, Kim SS, Cho YS, Lee SY, Noh BD. Comparison of linear polymerization shrinkage and microhardness between QTH-cured \& LED-cured composites. Oper Dent. 2005;30(4):461-7.

8. Franco EB, Lopes LG. Conceitos atuais na polimerização de sistemas restauradores resinosos. Biodonto. 2003;1(2):10-59.

9. Assmussen E, Peutsfeldt A. Light emitting diode curing: influence on selected properties of resin composites. Quintessence Int. 2003;34(1):71-5.

10. Rueggeberg FA, Caughman WF, Curtis JW. Effect of light intensity and exposure duration on cure of resin composite. Oper Dent. 1994;19(1):26-32.

11. Katahira N, Foxton RM, Inai N, Otsuki M, Tagami J. Comparison of PAC and QTH light sources on polymerization of resin composites. Am J Dent. 2004;17(2):113-7.

12. Craig RG, Powers JM. Materiais dentários restauradores. São Paulo: Santos; 2004.

13. Bedran-de-Castro AKB, Cardoso PEC, Ambrosano HMB, Pimenta LAF. Thermal and mechanical load cycling on microleakage and shear bond strength to dentin. Oper Dent. 2004;29(1):42-8.
14. Mitsui FHO, Peris AR, Cavalcanti AN, Marchi GM, Pimenta LAF. Influence of thermal and mechanical load cycling on microtensile bond strengths of total and self-etching adhesive systems. Oper Dent. 2006;31(2):240-7.

15. Nomoto R. Effect of light wavelength on polymerization of light-cured resins. Dent Mater J. 1997;16(1):60-73.

16. Habelitz S, Marshall Jr. GW, Balooch M, Marshall SJ. Nanoindentation and storage of teeth. J Biomech. 2002;35(7):9958.

17. Yap AUJ, Soh MS, Han VTS, Siow KS. Influence of curing lights and modes on cross-link density of dental composites. Oper Dent. 2004;29(4):410-5.

18. Feng LI, Carvalho R, Suh BI. Insufficient cure under the condition of high irradiance and short irradiation time. Dent Mater. 2009;25:283-9.

19. Rode KM, Freitas PM, Lloret PR, Powell LG, Turbino ML. Micro-hardness evaluation of a micro-hybrid composite resin light cured with halogen light, light-emitting diode and argon ion laser. Lasers Med Sci. 2009;24(1):87-92.

20. Ferracane JL, Berge HX, Condon JR. In vitro aging of dental composites in water - effect of degree of conversion, filler volume and filler/matrix coupling. J Biomed Mater Res. 1998;42(3):465-72.

21. Koin PJ, Kilislioglu A, Zhou M, Drummond JL, Hanley L. Analysis of degradation of a model dental composite. J Dent Res. 2008;87(7):661-5.

22. Yiu CKY, King NM, Pashley DH, Suh BI, Carvalho RM, Carilho MRO et al. Effect of resin hydrophilicity and water storage on resin strength. Biomaterials. 2004;25(26):5789-96.

23. Sideridou ID, Karabela MM, Vouvoudi EC. Dynamic thermomechanical properties and sorption characteristics of two commercial light cured dental resin composites. Dent Mater. 2008;24(6):737-43.

24. Calais JG, Söderholm KJM. Influence of filler type and water exposure on flexural strength of experimental composite resins. J Dent Res. 1988;67(5):836-40.

25. Braz AKS, Kyotoku BBC, Braz R, Gomes ASL. Evaluation of crack propagation in dental composites by optical coherence tomography. Dent Mater. 2009;25(1):74-9. 